\title{
Noções de Traumatologia Infantil em Medicina Geral e Familiar
}

João Lameiras Campagnolo*

\section{RESUMO}

Os conceitos que ditam o diagnóstico e o tratamento das lesões de etiologia traumática na criança (e no adulto) são, frequentemente, «diluídos» na enorme massa de informação fornecida durante a formação universitária e pós-graduada dos médicos.

Para poder ultrapassar estas limitações apresenta-se, de forma genérica, a fisiopatologia, a epidemiologia e a semiologia a valorizar num quadro de traumatologia infantil; também são apresentados alguns princípios terapêuticos para solucionar uma parte significativa destas situações.

Palavras-chave: Traumatologia; Criança; Medicina Geral e Familiar.

\section{INTRODUÇÃO (EPIDEMIOLOGIA)}

A s lesões osteoarticulares de causa traumática são muito frequentes nas crianças e são devidas, essencialmente, a traumatismos sofridos, quer durante a sua actividade desportiva, quer durante as simples «brincadeiras» inerentes à sua actividade diária; a seguir, e em termos estatísticos, temos as causas rodoviárias (atropelamentos e acidentes de viação) que provocam, habitualmente, lesões muito mais graves e de tratamento mais complexo.

Atendendo a que as lesões em causa atingem um organismo em fase de crescimento, as consequências podem ser agravadas pela afecção das cartilagens de crescimento. Estas cartilagens, situadas nas regiões epifisiometafisárias dos ossos longos e responsáveis pelo crescimento em comprimento destes ossos, têm uma actividade de crescimento que diverge consoante a sua localização (Figura 1).

\section{FISIOPATOLOGIA}

O osso da criança tem particularidades que o distinguem do osso do adulto na composição, na fisiologia e na morfologia. ${ }^{1}$ Estas particularidades vão condicionar o tipo de lesões encontradas neste escalão pediá-

*Médico Assistente em Ortopedia

Serviço de Ortopedia, Hospital Da Estefânia - CHCL, Lisboa, Portugal trico. Com efeito, para além da já referida presença das cartilagens de crescimento (Figuras 2 e 3), existe um periósteo espesso e resistente, uma relação matriz/osso elevada (o que condiciona uma maior elasticidade óssea) e um elevado turnover ósseo (que permite uma maior capacidade de reparação mas, também, um ris-

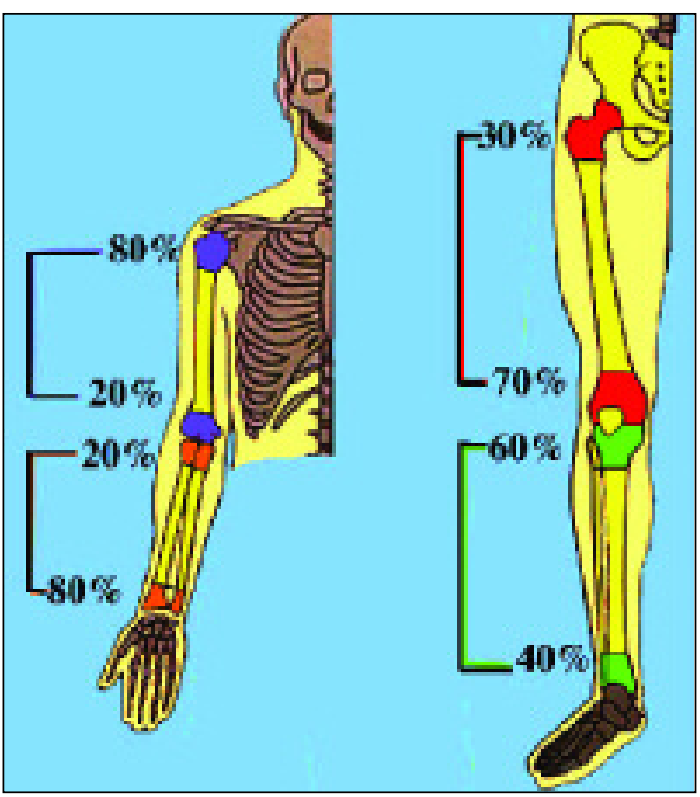

Figura 1. Cartilagens de crescimento dos ossos longos dos membros, com respectiva proporção no crescimento ósseo até à fase adulta. 


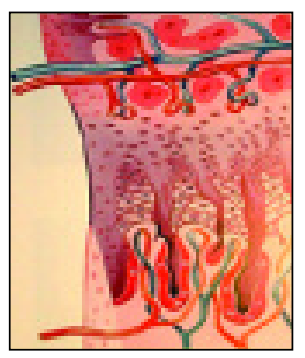

Figura 2. Esquema histológico da zona da cartilagem de crescimento.

co de agravamento das deformidades provocadas).

No que respeita à distribuição das lesões em função do escalão etário é necessário relacionar os mecanismos lesionais com as lesões provocadas, entendendo-se que certo tipo de lesão vai ocorrer, ou porque há maior probabilidade para que o mecanismo lesional ocorra (pelo tipo de actividade da criança ou da dos que cuidam desta) e/ou porque, naquela fase de crescimento, certa região anatómica é mais susceptível de sofrer uma lesão. Assim, observamos mais frequentemente:

- no recém-nascido: fractura da clavícula, torcicolo, fractura do fémur;

- nos primeiros 2-4 anos de vida: pronação dolorosa, fractura do fémur;

- entre os 5-8 anos: fractura supra-condiliana do úmero, fractura distal do rádio;

- na infância tardia/adolescência: fracturas dos ossos do antebraço (e outros ossos longos), lesões de «sobre-uso»/osteocondroses (calcâneo, tuberosidade anterior da tíbia ou pólo inferior da rótula, navicular, ...), lesões das fises em fase de encerramento, para além de lesões com padrão já semelhante ao do adulto.

Naturalmente que são de considerar, ainda, todas as lesões resultantes de traumatismos graves, como atropelamentos, acidentes de viação ou quedas de grande altura.

Também nunca é de mais salientar a síndroma da criança maltratada, para a qual os profissionais de saúde devem estar particularmente atentos; fracturas múltiplas, fracturas isoladas de ossos longos, necroses dos dedos (ou, nalguns casos, dos genitais) causadas por corpos estranhos (fios, cabelos) devem ser particularmente avaliados, para não deixar passar um caso de potencial risco de vida.

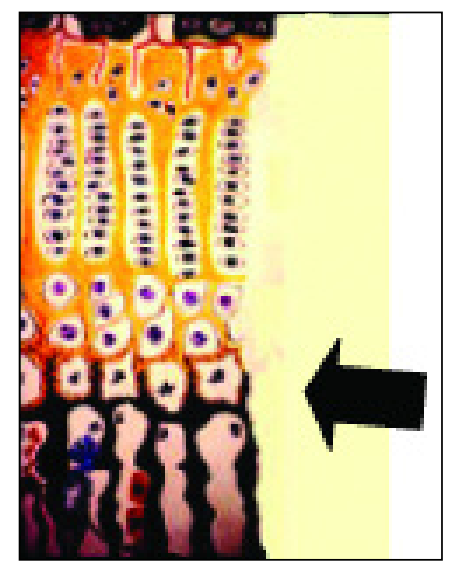

Figura 3. Zona de fragilidade mecânica da cartilagem de crescimento (zona hipertrófica).

Finalmente, devemos ter presente que as fracturas nas crianças têm algumas particularidades no que toca à sua consolidação:

- Rapidez de consolidação (tanto maior quanto mais nova for a criança);

- Quasi-ausência de algumas complicações observáveis no adulto, tais como as pseudartroses;

- Risco de hiper-crescimento a nível do foco de fractura, que se verifica até aos 18-24 meses pós fractura e que é, geralmente, mais marcado após cirurgia de reparação óssea (osteossíntese);

- Remodelação óssea que corrige defeitos de alinhamento axial (mas não rotacional) das fracturas; esta capacidade de remodelação é tanto mais importante quanto mais jovem é a criança;

- Risco de atraso de crescimento (por vezes irreversível), simétrico ou assimétrico, consoante o atingimento das cartilagens de crescimento; há, também, fracturas extra-fisárias que têm repercussão fisária transitória (testemunhada, a posteriori, pela presença de linhas de Harris metafisárias).

\section{SEMIOLOGIA CLÍNICA}

A semiologia é relativamente repetitiva (dor, impotência funcional, deformidade e eventuais sinais inflamatórios locais), mas com duas dificuldades acrescidas à semiologia do adulto: habitual má colaboração na anamnese e na localização exacta da dor e, por vezes, existência de dores referidas a outras áreas anatómicas (por exemplo, joelho versus anca), que podem falsear 
ou escamotear o diagnóstico da lesão verdadeira. ${ }^{2,3}$ Por vezes, nas crianças mais jovens, o único sinal de uma lesão do aparelho músculo-esquelético pode ser uma «pseudo-paralisia» de todo um membro, pelo que o exame clínico deverá ser particularmente atento.

\section{EXAMES COMPLEMENTARES DE DIAGNÓSTICO}

Nos casos em que o diagnóstico exclusivamente clínico não é conseguido, pode ser necessário o recurso à radiografia simples da área suspeita (em 2 planos ortogonais e, por vezes, de forma comparativa com o lado contrário ao da lesão). Nas crianças mais jovens com lesões de áreas ainda cartilagíneas a ecografia, efectuada por profissionais devidamente preparados, pode ser um precioso contributo diagnóstico. Também a cintigrafia é um importante exame de $2^{\mathrm{a}}$ linha para detectar algumas lesões sem evidência de repercussão radiológica (lesões de «sobre-uso» ou de regiões de difícil caracterização radiológica, tais como a coluna). Finalmente, em casos seleccionados, a tomografia axial computorizada ou a ressonância magnética podem ser necessárias.

\section{CLASSIFICAÇÃO}

As classificações das fracturas e outras lesões osteoarticulares são adequadas a cada osso/articulação afectados e são relativamente complexas, pelo que não se adequam neste contexto; salientam-se, apenas, os diferentes tipos de lesão das fises (cartilagens de crescimento), referindo que os últimos 3 graus são aqueles em que o risco de sequela (dismetria e/ou desalinhamento axial do membro) é muito mais elevado, por afectarem a camada germinativa da cartilagem de crescimento (Figura 4).

\section{DIAGNÓSTICO DIFERENCIAL}

Na criança e consoante a idade, devem excluir-se os quadros de artrite infecciosa ou inflamatória, de epifisiólise femoral proximal (por vezes também de origem «macro-traumática»), de doença de Perthes ou de lesão tumoral ou pseudo-tumoral (presença de quisto ósseo, por exemplo).

\section{ATITUDE/PROCEDIMENTOS DO MÉDICO DE FAMÍLIA}

Na grande maioria dos casos, as lesões osteoarticulares da criança não apresentam repercussões funcionais

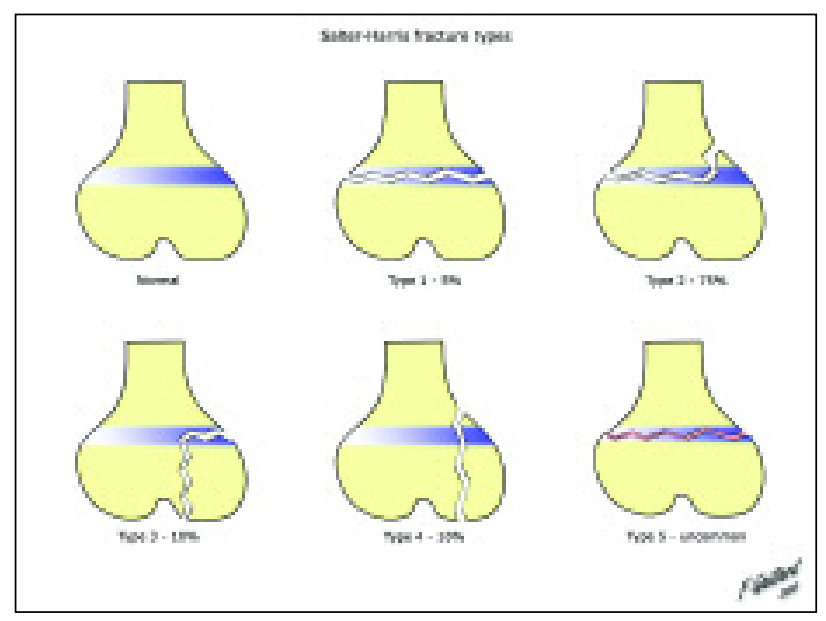

Figura 4. Classificação de Salter-Harris das fracturas-epifisiolise.

a longo prazo e devem ser tratadas de forma relativamente simples, o que não significa abstenção terapêutica.

Por conseguinte, e nestas situações, a instituição de várias medidas é necessária, sendo as mais frequentes:

- a descarga do membro afectado (o que, no membro inferior, implica o uso de 2 canadianas, para as crianças colaborantes, e o repouso no leito para as outras);

- a elevação do membro afectado durante a fase de edema e dor;

- a crioterapia local (cerca de 15 minutos, de duas em duas horas, durante 2-3 dias);

- a contenção local (contenção elástica, com ligadura, por exemplo, ou contenção rígida, consoante a gravidade);

- a instituição de uma terapêutica analgésica e/ou anti-inflamatória adequada, quando as precedentes medidas forem insuficientes.

O período de instituição destas medidas deve respeitar a ausência de dor e o tempo mínimo de cicatrização/consolidação das estruturas envolvidas, o que implica uma vigilância de no mínimo, duas a três semanas. Em caso de dúvida, e em tempo útil (2-3 dias), a criança deverá ser encaminhada para um Ortopedista.

Um caso particular é o da chamada "pronação dolorosa» encontrada, habitualmente, entre o $1^{\circ}$ e o $4^{\circ}$ ano de vida; o mecanismo de génese desta situação é relativamente frequente; trata-se de «um puxão» de um dos membros superiores, ou de uma queda de uma crian- 


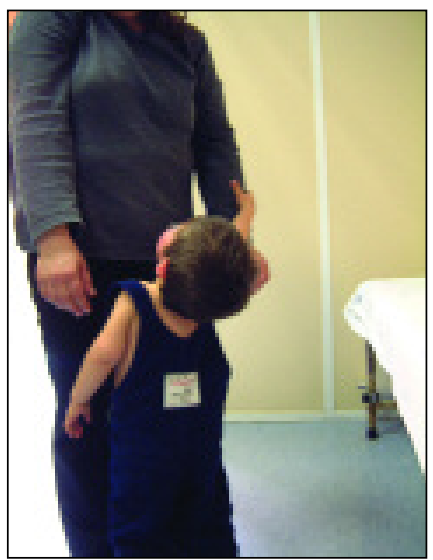

Figura 5. Aspecto típico de criança com pronação dolorosa, com o «braço pendente».

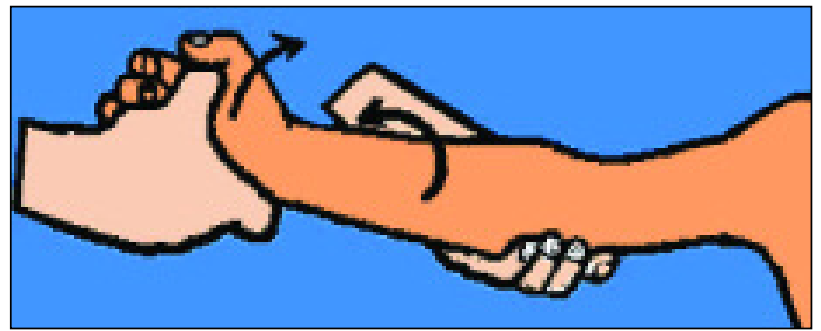

Figura 6. Esquema de tratamento com hiper-supinação e extensão do cotovelo

ça quando esta é segurada por alguém, pela mão. A história de traumatismo é, habitualmente, negada.

A observação revela, geralmente, um membro superior «pendente» (Figura 5), com limitação funcional evidente (pronação dolorosa e supinação limitada); uma eventual radiografia não mostra alterações.

Existem várias técnicas de redução ${ }^{1,4}$ que consistem, mormente, em forçar a supinação, por vezes após um breve período de tracção e/ou hiperpronação, verificando o sucesso da manobra com hiper flexão e extensão do cotovelo em supinação (Figuras 5 e 6), sentindo-se habitualmente um «clic» correspondendo à redução da tacícula radial.

Outra situação a referir, pela sua grande incidência, é a dos traumatismos do tornozelo e/ou pé designados, habitualmente, como «entorses do tornozelo».

Nestes casos, e particularmente nas crianças, há que ter um especial cuidado no uso fundamentado deste «diagnóstico»; com efeito, e até aos 12-14 anos de idade (consoante o sexo e a maturidade sexual da criança

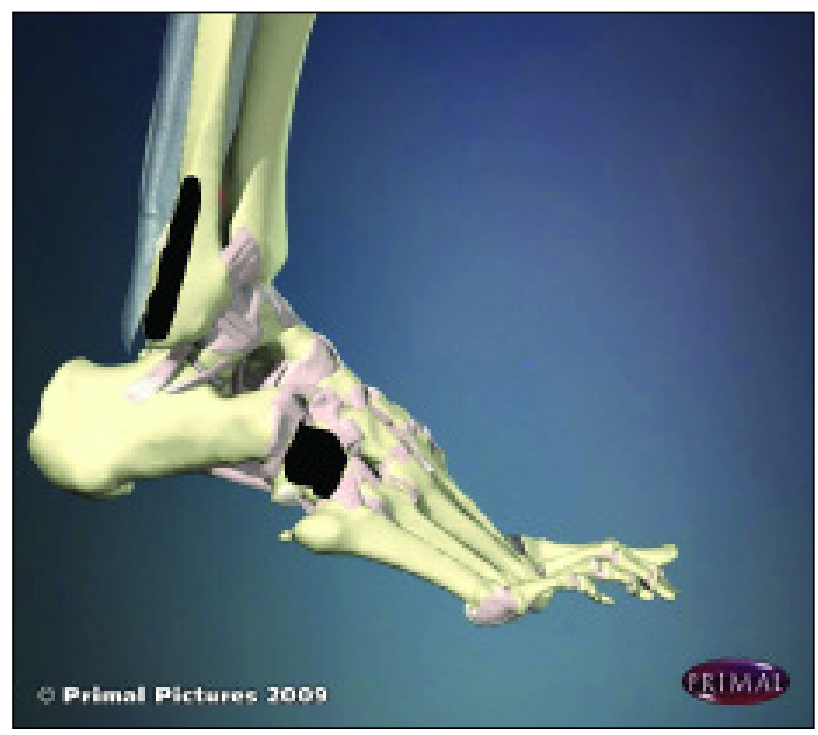

Figura 7. Critérios de Ottawa para solicitação (ou não) de radiografia, após lesão aguda do tornozelo/pé ${ }^{5}$ - vista da face lateral - externa do tornozelo - pesquisa de dor a nível do cuboide e do maléolo externo

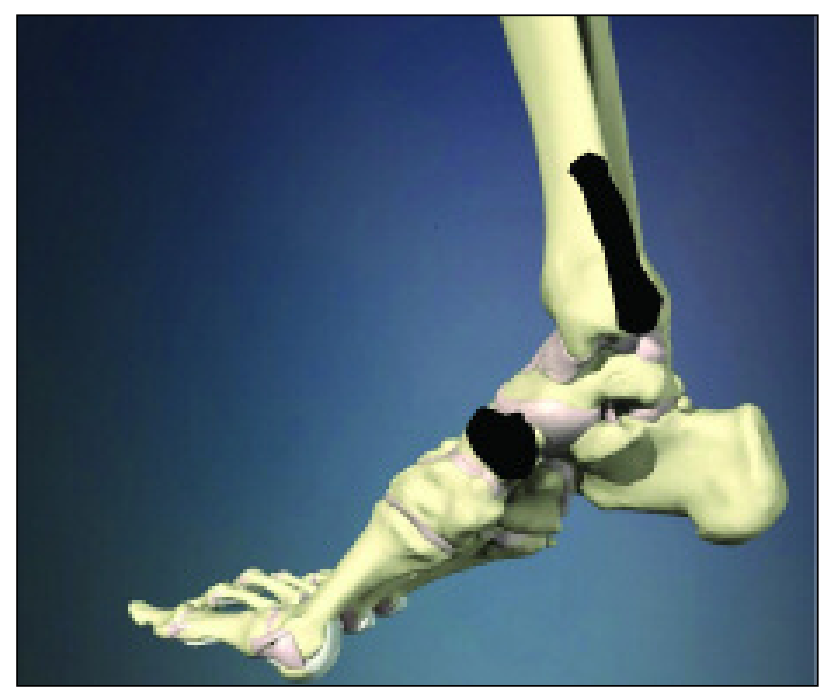

Figura 8. : Critérios de Ottawa para solicitação (ou não) de radiografia, após lesão aguda do tornozelo/pé ${ }^{5}$ - vista da face medial interna do tornozelo - pesquisa de dor a nível do navicular (escafoide társico) e do maléolo interno (Imagem Univadis - MSD)

Segundo os critérios de Ottawa, um estudo radiográfico do tornozelo é necessário APENAS se houver dor nas zonas sombreadas:

- Últimos $6 \mathrm{~cm}$ do bordo posterior do maléolo externo

- Base do $5^{\circ}$ metatarso

- Últimos $6 \mathrm{~cm}$ do bordo posterior do maléolo interno

- Região do navicular (escafóide társico) ou

- se houver incapacidade de marcha, quer após o acidente, quer durante a observação pelo Médico 
e, também, consoante o mecanismo lesional do traumatismo), a cartilagem de crescimento é biomecanicamente mais frágil que os ligamentos presentes nessa região anatómica. Por esta razão, podemos estar perante uma fractura-epifisiólise (embora muitas vezes «invisível» nas radiografias simples) e não perante uma «simples» entorse...

Alguns países aplicam os «critérios de Ottawa» para avaliação da necessidade de requisição de radiografia nestas situações. ${ }^{5}$ Nalguns dos nossos hospitais, estes critérios começam a ser usados nos serviços de Urgência e podem ser um guia importante na prática quotidiana, por permitirem uma redução do número de exames (neste caso inúteis) e pela sua importância no contexto médico-legal.

Assim, pelos critérios de Ottawa, apenas deverão ser pedidos exames radiográficos do tornozelo quando um doente, com dor nesta área após lesão aguda (mecanismo habitual de torsão do tornozelo), apresenta um ou mais dos critérios seguintes:

Dor à palpação do maléolo externo e/ou interno (últimos $6 \mathrm{~cm}$, nas suas vertentes mais posteriores - ver $\mathrm{Fi}$ gura 8);

- Dor à palpação do navicular (escafóide társico);

- Dor à palpação do cubóide;

- Incapacidade total de carga em ortostatismo;

- Incapacidade para marcha (incapacidade de dar mais de 2 passos após o traumatismo);

- Idade superior a 55 anos (critério fora do âmbito deste artigo).

Quando nenhum destes critérios está presente, poder-se-á tranquilizar os pais (será amiúde a parte mais complicada da nossa prática clínica...), explicando que a radiografia não será necessária para a decisão terapêutica (sendo antes deletéria pela radiação implicada desnecessariamente); o tratamento será igual e passará pelas orientações preconizadas no início deste capítulo.

Como não temos forma de distinguir radiologicamente uma entorse sem avulsão óssea de uma fractura-epifisiólise de tipo I não descoaptada (estes dois diagnósticos cobrem a grande maioria das lesões agudas do tornozelo na criança), o tratamento será idêntico, avisando da necessidade de descarga de 2 a 3 semanas, até se obter uma ausência total de dor e de edema local.

Por fim, os casos de maior gravidade - ou seja aqueles que apresentam risco vital, aqueles em que há de- formidades major (com ou sem exposição óssea) ou os casos em que há um quadro álgico significativo, mesmo em repouso - deverão ser rapidamente encaminhados para um serviço de Urgência (com Ortopedista disponível, de preferência).

\section{PERSPECTIVA DO PLANO TERAPÊUTICO DO CIRURGIÃO ORTOPÉDICO}

No escalão pediátrico, as lesões osteoarticulares atingem, preferencialmente, o osso e a cartilagem de crescimento, sendo raras as lesões ligamentares. Neste contexto, queixas articulares pós-traumáticas sem lesão radiologicamente visível podem ser interpretadas, consoante a clínica, como lesões da cartilagem de crescimento (geralmente do $1^{\circ}$ grau, mais benignas), com a consequente necessidade de imobilização do segmento afectado.

Actualmente, as fracturas dos ossos longos têm tido um aumento relativo das suas indicações cirúrgicas, fruto de três ordens de factores: alta energia de alguns acidentes (rodoviários e desportivos), surgimento de técnicas cirúrgicas com muito boa relação «custo-benefício» (tal como o encavilhamento elástico dos ossos) e progressiva redução dos tempos de internamento/imobilização do doente. No entanto, e apesar deste facto, a grande maioria das fracturas consolida rapidamente e sem sequelas valorizáveis.

No caso das fracturas com desvios nos planos frontal e sagital (e sem atingimento da cartilagem de crescimento), como precedentemente referido, pode não haver necessidade de redução, desde que o desvio não exceda cerca de $10-20^{\circ}$ (variável consoante a idade); no entanto, desvios rotacionais no foco de fractura implicam a sua correcta redução e imobilização.

Finalmente, no que refere às lesões articulares e como princípio básico, todas as fracturas deverão ser reduzidas anatomicamente e assim mantidas, por meios incruentos ou cruentos. Quando assim não acontece e/ou quando a própria lesão destruiu parcial ou totalmente a cartilagem de conjugação, são as sequelas destas lesões que colocam os maiores problemas a resolver no campo da traumatologia infantil; serão, então, necessários diferentes tipos de estratégias cirúrgicas (realinhamentos, alongamentos, desepifisiodeses, encurtamentos contra-laterais...) para minimizar as repercussões na vida da criança afectada, futuro adulto 
integrando a nossa sociedade.

\section{REFERÊNCIAS BIBLIOGRÁFICAS}

1. Herring JA. Tachdjian's Pediatric Orthopaedics. 3rd ed. Philadelphia: W.B. Saunders; 2002.

2. Staheli LT. Fundamentals of Pediatric Orthopedics. 3rd ed. Philadelphia: Lippincott, Williams \& Wilkins; 2003.

3. Seabra J. Conceitos básicos de ortopedia infantil. $3^{\text {a }}$ ed. Coimbra: ASIC; 2000.

4. Lerat JL. Orthopédie, sémiologie, traumatologie, base de données pour l'enseignement. Paris: Collège Français des Orthopédistes et Traumatologues; 2005.

5. Stiell IG, Wells G, Laupacis A. Brison R, Verbeek R, Vandemheen K, et al. Multicentre trial to introduce the Ottawa ankle rules for use of radiography in acute ankle injuries. Multicentre Ankle Rule Study Group. BMJ1995 Sep 2; 311 (79005): 594-7.
Os autores declararam não possuir conflitos de interesses

\author{
ENDEREÇO PARA CORRESPONDÊNCIA \\ João Lameiras Campagnolo \\ Serviço de Ortopedia, Hospital Da Estefânia \\ Rua Jacinta Marto, 1169 Lisboa, Portugal \\ E-mail: campas@iol.pt
}

\section{ABSTRACT}

\section{PAEDIATRIC TRAUMATOLOGY NOTIONS IN FAMILY PRACTICE}

During pre and post graduation in Medicine, the traumatic aetiology concepts that guide the diagnosis and treatment of lesions in children (and adults) are often watered down in the immensity of medical knowledge to which medical students are subjected.

Despite being frequently confronted with cases of paediatric traumatology, family physicians often feel they are poorly prepared to evaluate and treat these cases.

In order to surpass these limitations, a few notions of physiopathology, epidemiology, semiology - common in a context of paediatric traumatology - are presented. Some general therapeutic principles that allow to solve a number of these situations are also discussed.

Keywords: Traumatology; Child; Family Practice; Family Physician. 